Gadjah Mada International Journal of Business

September 2004, Vol. 6, No. 3, pp. 405—418

\title{
THE RELATIONSHIPS BETWEEN BELIEF, ATTITUDE, SUBJECTIVE NORM, AND BEHAVIOR TOWARDS INFANT FOOD FORMULA SELECTION The Views of the Malaysian Mothers
}

\author{
T. Ramayah \\ Aizzat Mohd. Nasurdin \\ Mohd. Nasser Noor \\ Quah Boon Sin
}

The purpose of the study is to determine the relationships between belief, attitude, subjective norm, intention, and behavior towards the choice of infant food based on the Theory of Reasoned Action (TRA). An analysis on a sample of 108 mothers indicates that the TRA could be used in predicting choice decision of infant food formulas by explaining 57 percent of the variance in the behavioral intention. The subjective norm component had a higher predictive power than the attitudinal component. Of this normative component, parents or relatives and doctors were found to be more influential. Intention to choose an infant formula was also influenced by family income. The belief outcomes in evaluating a premium infant formula and economic infant formula were found to be different. For premium infant formula, brand trusted, closest to breast milk and nutrients content were identified as the dominant attributes. In contrast, availability, affordable, and nutrients content were identified as the prime beliefs in evaluating economic infant formula. Implications of the findings are discussed.

Keywords: attitude; behavior; belief; infant food formula; intention; Malaysian mothers; subjective norm; Theory of Reasoned Action 


\section{Introduction}

Breastfeeding has been a traditional practice among Malaysian women (Manderson 1984). Nevertheless, the introduction of breast-milk substitutes such as condensed and dehydrated milk since the late nineteenth century and the subsequent marketing of commercially manufactured infant foods have led to some variations in this feeding pattern (Manderson 1984). Additionally, urbanization, female participation in the labor force, increased availability of processed milks and their extensive promotion by manufacturers and the health sector, and regimentation of breast-feeding, have now led to the widespread use of processed milk as substitutes for breast-milk and supplements for very young infants.

In Malaysia, the infant nutritional market is said to be growing at a relatively fast rate. For example, in the year 2000 , the growth rates for the overall market for first-age infant formulas and follow-on infant formulas were 2.5 percent and 5.6 percent respectively (Nielsen 1999). The greater demand for nutritional food for infants is further compounded by the increasing awareness among mothers for healthy babies. Despite this rapid growth in consumption of infant food, very limited studies have investigated the pattern of infant feeding within the Malaysian context (Manderson 1984; King and Ashworth 1987). Since the cognitive processes within the individual is important in influencing a consumer's food choices (Conner 1993), it would be beneficial for food manufacturers to understand these processes in order to plan appropriate marketing strategies. Furthermore, given that the theory of reasoned action (Ajzen and Fishbein 1980) has been shown to have good predictive power in studies on food preferences and consumption abroad (for instance, Matheny et al. 1987; Towler and Shepard 1992; Thompson et al. 1994; Brewer et al. 1999), the objective of this study is to assess the efficacy of this theory as a predictor of infant formula usage among local mothers. Again, one of our objectives is to ascertain if the TRA can be applied in a developing country like Malaysia where the people value family and family ties (Mansor 1992). In addition, this study also to examine the role of normative factors in predicting infant formula usage.

\section{Infant Nutritional Market}

The definition of infant formula market refers to the infant formula market for infants under one year old. In general, the infant market is segmented into first-age formula and follow-on formula. First-age formula is milk powder designed for consumption of infants less than six months whereas follow-on formula is that for the consumption of infants with age from six months to one year. In Malaysia, the infant formula market is divided into 2 categories: premium infant and economy infant. The key attributes that differentiate these categories of formula are price and formulation. In general, premium infant formulas are marketed at higher price, that is, more than RM30 per kilogram whereas economic infant formulas are priced at less than RM20 per kilogram. In terms of formulation, premium infant formulas are modified cow's milk formulas whereby its nutrient contents are modified to the physiologic level of human breast milk. It contains the necessary levels of all essential nutrients similar to those found in human milk to satisfy the nutritional needs of the babies. Economic formulas are unmodified cow's milk formulas. It contains the 
Ramayah et al.-The Relationships between Belief, Attitude, ...

recommended amounts of all the essential nutrients to satisfy the nutritional needs of the babies.

The countries of origin for most premium infant formulas are from Europe whereas most of the economic infant formulas are manufactured in Australia or New Zealand. In Malaysia, the infant nutritional market is relatively large. For instance, in 1998, the total market value for first-age infant formulas amounted to RM84 million. The premium category and economy category contributed 47 percent and 53 percent respectively to the first-age infant market. As for the follow-on infant formula, in 1998, the total market amounted to RM79 million whereby the premium category and economy category contributed 48 percent and 52 percent respectively. The infant nutritional market is also said to be growing at a relatively fast rate. For example, in the year 2000, the growth rates for the overall market for first-age infant formulas and follow-on infant formulas were 2.5 percent and 5.6 percent respectively (Nielsen 1999).

\section{Literature Review}

\section{Theory of Reasoned Action}

Attitude has been found to be a significant intervening variable in explaining and predicting choice behavior among consumers (Howard and Sheth 1969; Howard 1989). In the study of attitudes, two of the early mathematical models which were associated with the so-called expectancy-value theories are Rosenberg's Instrumentality-Value model (1956) and Edwards' Subjective Expected Utility model (1954). However, a major limitation of these models was that they failed to include certain critical elements such as: a) behavioral intention as a precursor to behavior, b) the importance of sociallybased beliefs, and c) the potential importance of socially-based beliefs (expectations) about the attitude object. Such omissions have resulted in a weak prediction of behavior (Bass and Talarzyk 1972; Fishbein 1971). Subsequently, the beliefevaluation model was introduced by Fishbein (1967) and later elaborated by Fishbein and Ajzen (1975). This theoretical framework attempts to alleviate the problems associated with earlier models proposed by Rosenberg (1956) and Edwards' (1954) by incorporating the three important elements listed above. Over the years, this model has been refined, developed and tested (Ajzen and Fishbein 1980).Today, the model known as the theory of reasoned action or TRA (Ajzen and Fishbein 1980) is considered the most widely applied model of beliefs and attitudes in social psychology (Grube et al. 1986).

According to the TRA framework (Ajzen and Fishbein 1980), the performance or non-performance of a specific behavior is determined by the intention to perform that behavior. Thus, behavioral intention is the immediate determinant of actual behavior. Based on the TRA model (Ajzen and Fishbein 1980), two basic factors determine a person's behavioral intentions: (1) the person's attitude toward the behavior, and (2) the subjective norm.

Algebraically, the TRA model(Ajzen and Fishbein 1980) is expressed as:

$\mathrm{B} \sim \mathrm{I}=\left(\mathrm{A}_{\mathrm{B}}\right) \mathrm{w}_{1}+(\mathrm{SN}) \mathrm{w}_{2} \longrightarrow\left(\mathrm{E}_{1}\right)$

Where:

$\mathrm{B}=$ behavior

I $=$ the person's intention to perform the behavior 
$\mathrm{A}_{\mathrm{B}} \quad=$ the person's attitude toward performing behavior

$\mathrm{SN}=$ subjective norm

$\mathrm{w}_{1}$ and $_{\mathrm{w}_{2}}=$ empirically determined weights

An individual's attitude represents an individual's personal convictions and feelings towards a specific behavior. Generally, a person who believes that performing a given behavior will lead to positive outcomes will hold a favorable attitude toward performing the behavior. On the other hand, a person who believes that performing a given behavior will lead to negative outcomes will hold an unfavorable attitude toward performing the behavior. According to the TRA model (Ajzen and Fishbein 1980), attitude toward the behavior is jointly determined by one's salient beliefs that the behavior leads to certain outcomes, and by that person's evaluation of these outcomes.

Mathematically, it can be written as

$A_{B}=\sum b_{i} e_{i}$, for $i=1$ to $n$ $\left(\mathrm{E}_{2}\right)$

where:

$\mathrm{A}_{\mathrm{B}}=$ attitude toward performing the behavior;

$b_{i}=$ the person's belief that performing the behavior will result in outcome $i$;

$\mathrm{e}_{\mathrm{i}}=$ the person's evaluation of outcome $i$;

$\mathrm{n}=$ the number of beliefs.

According to Ajzen and Fishbein (1980), an individual's subjective norm relates to a person's belief that most of his/ her importance others think how he/she should (should not) perform the behavior in question. This definition implies that in forming a subjective norm, an individual takes into account the normative expecta- tions of various others in his/her environment. In other words, the subjective norm reflects the person's perception of social pressures put on him/her to perform or not to perform the behavior in question. A strong relationship is said to exist when the source was someone who knew the decision-maker personally and weak-tie if the source was merely an acquaintance or one who did not know the decision-maker at all (Miniard and Cohen 1981). Hence, the more a person perceives that others who are important to him/her think he/she should perform a behavior, the more he/ she will intend to do so (Ajzen and Fishbein 1980). Two factors are said to contribute to the subjective norm. The first factor relates to one's normative belief. Normative beliefs are based on what is the expected reaction of important figures in an individual's life. The second factor relates to one's motivation to comply, which is the extent to which the individual wishes to comply with the wants and needs of important figures. Motivation to comply is measured by asking respondents to rate how much they want to conform to other people's desires. In sum, an individual's subjective norm is a multiplicative combination of his/her salient normative beliefs regarding "doing what other people want me to do" and his/her motivation to comply with the expectations of "these" people.

The equation for obtaining the subjective norm is:

$\mathrm{SN}=\Sigma \mathrm{NB}_{\mathrm{j}} \mathrm{MC}_{\mathrm{j}}$, for $\mathrm{j}=1$ to $\mathrm{n}$ $\left(\mathrm{E}_{3}\right)$

where:

$\mathrm{SN}=$ subjective norm;

$\mathrm{NB}_{\mathrm{j}}=$ the normative belief that a reference group $j$ thinks that the person should or should not perform the behavior; 
Ramayah et al.-The Relationships between Belief, Attitude, ...

$\mathrm{MC}_{\mathrm{j}}=$ the motivation to comply with the influence of referent $j$;

$\mathrm{n} \quad=$ the number of relevant reference groups of individuals.

\section{Theoretical Framework and Hypotheses}

This study utilizes the TRA model (Ajzen and Fishbein 1980) given the ability of the model to predict health-related behaviors such as breast-feeding as discovered by previous scholars (for instance, Manstead et al. 1983, Kessler et al. 1995, Kloeben and Thompson 1999). The conceptual framework is shown in Figure 1.
Hence, the hypotheses posited in this study are as follows:

$H_{1}$ : The intention to select an infant formula [either premium (Brand X) or economic (Brand Y)] is influenced by a person's attitude towards the behavior and his/her subjective norm.

$\mathrm{H}_{2}$ : The more positive is the attitude towards the behavior, the greater is the intention to perform the behavior.

$H_{3}$ : The more positive is the subjective norm, the greater is the intention to perform the behavior.

$H_{4}$ : Behavioral intention can be used to discriminate whether a person will buy a premium or economic brand infant formula.

\section{Figure 1. Theoretical Framework}

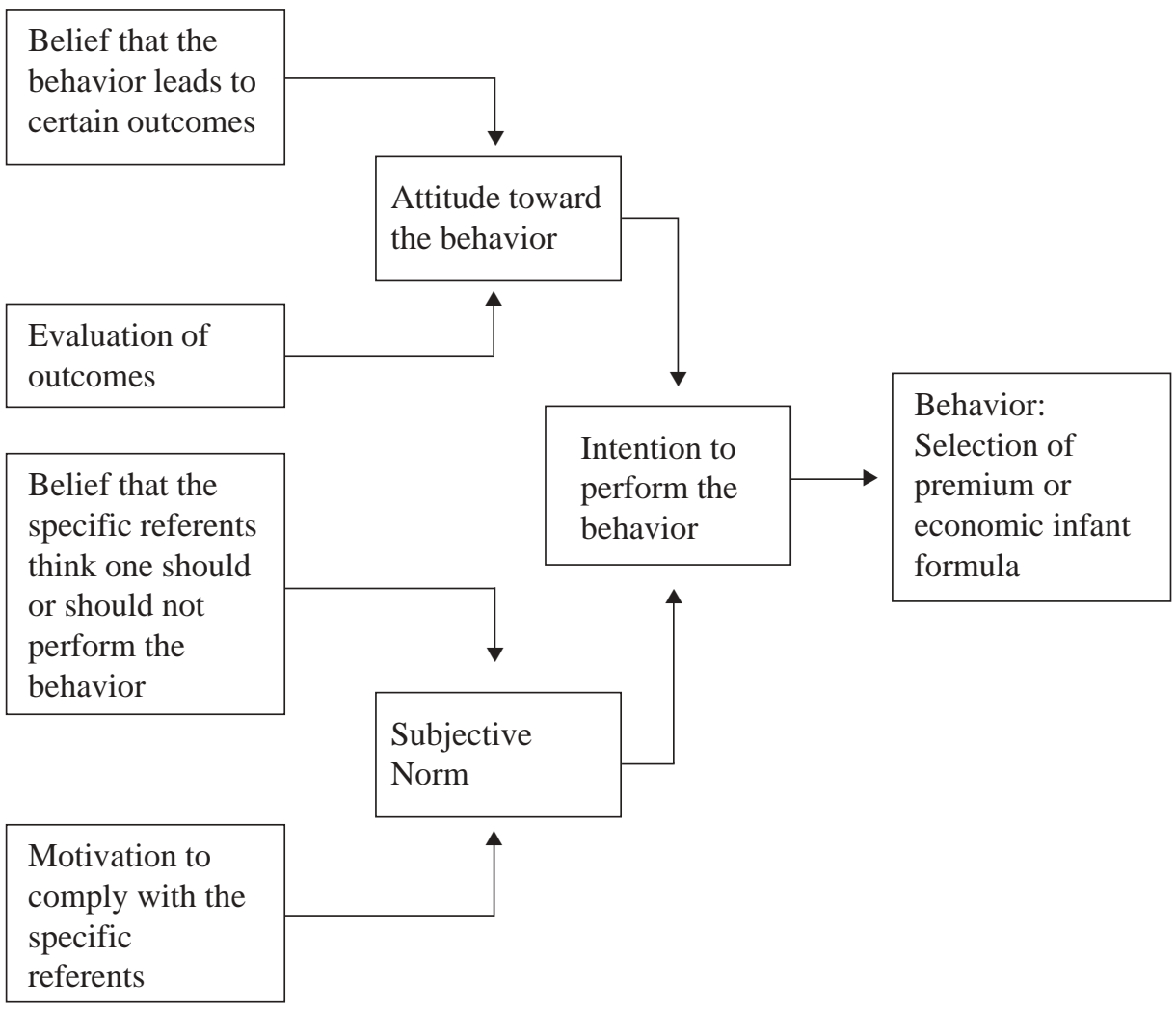




\section{Methodology}

\section{Subjects and Procedure}

The population for this study comprised of pregnant mothers or mothers with at least one child and these women were ready to bottle-feed or have bottlefed their baby/babies residing on the Island of Penang and its mainland. A total of 200 mothers were sampled using purposive sampling based on the above-mentioned criteria.

A structured questionnaire was used to collect the data. The structure of the questionnaires was based on the standard questionnaire developed by Ajzen and Fishbein (1980). Questionnaires were distributed with the help of selected volunteers.

The following are examples of the statement used to assess the attitudes to behavior and subjective norms.

1. Behavioral beliefs. "Using brand $X$ formula is very likely/very unlikely to give me a formula that satisfies the nutritional needs of my baby." There were 14 such statements 7 for each infant food formula measured on a 5point Likert-type scale anchored by "very likely" $(+2)$ to "very unlikely" (2) with "no opinion" (0) as a midpoint.

2. Evaluation of outcomes. "Using an infant formula that is closer to breast milk is very good/very bad." Each statement in the belief section corresponded with one statement in the evaluation section measured on a 5-point Likerttype scale anchored by "very good" $(+2)$ to "very bad" $(-2)$.

3. Normative beliefs. "My family and relatives thinks I should / should not use formula X." There were 4 such statements for each type of infant formula with a different referent each time. Each statement in the normative belief section was measured on a 5point Likert-type scale anchored by "definitely should" to "definitely should not."

4. Motivation to comply. "Typically, I like to do what my family suggests that I do." Each statement in the normative beliefs section corresponded with one statement in the motivation to comply section for each referent measured on a 5-point Likert-type scale ranging from "always" to "never."

5. Behavioral Intention. "All things considered, what are the chances that you will feed your baby with brand $\mathrm{X}$ infant formula?" This one item will be repeated for both type of infant food formula and was measured using a 5point Likert-type scale ranging from "very likely" to "very unlikely."

\section{Results}

Based upon a series of focus group interviews with 20 randomly selected mothers yielded 7 belief outcomes and 4 influence referents. Salient beliefs relate to: (1) Closest to breast milk - whether the formula is modified closer to breast milk or just normal cow milk, (2) Visible in the babies' physical and mental development — whether the formula helps to develop the full potentials of the babies, (3) Nutrients contents - whether the formula satisfies the nutritional needs of the babies, (4) Availability - whether the formula is easy to locate or easy to buy, (5) Affordable - whether the formula is priced at affordable level, (6) Baby acceptance - whether the formula is well accepted or tolerated by the baby, and (7) Brand trusted - whether the formula is of a trusted brand. On the other hand, influenced referents identified include parents and relatives, doctors, nurses, and friends. 
Ramayah et al.-The Relationships between Belief, Attitude, ...

The 7 major salient belief attributes and 4 major normative belief attributes were used to construct closed-ended questions which included items measuring all the beliefs, evaluative components, attitude towards behavior, normative beliefs, motivation to comply, subjective norm, intention, and choice behavior.

\section{Response Rate}

Of the 200 questionnaires distributed, 140 questionnaires were collected, representing a response rate of 70 percent.
However, only 108 useable questionnaires were analyzed. Table 1 depicts the demographic profile of the respondents.

From Table 1, 62 percent of the respondents were below 35 years of age. In terms of race, a majority (56\%) of the respondents were Chinese. Half of the sample had tertiary education. Regarding occupation, 52.8 percent of the respondents were white-collar workers. In terms of family income, 61.1 percent of the sample came from families whose earnings were less than RM4000 per month.

\section{Table 1. Demographic Profile of Respondents}

\begin{tabular}{|c|c|c|}
\hline Demographic Variable & Frequency & Percentage $(\%)$ \\
\hline \multicolumn{3}{|l|}{ Age (years) } \\
\hline Below 20 & 1 & 0.9 \\
\hline 20 То 27 & 12 & 11.1 \\
\hline 28 То 34 & 54 & 50.0 \\
\hline 35 То 40 & 33 & 30.6 \\
\hline Above 40 & 8 & 7.4 \\
\hline \multicolumn{3}{|l|}{ Race } \\
\hline Malay & 37 & 34.3 \\
\hline Chinese & 61 & 56.5 \\
\hline Indian & 8 & 7.4 \\
\hline Others & 2 & 1.9 \\
\hline \multicolumn{3}{|l|}{ Education Level } \\
\hline Primary & 4 & 3.7 \\
\hline Secondary & 50 & 46.3 \\
\hline Diploma or Degree & 54 & 50.0 \\
\hline \multicolumn{3}{|l|}{ Occupation } \\
\hline Housewife & 13 & 12.0 \\
\hline Self Employed & 5 & 4.6 \\
\hline Blue Collar & 33 & 30.6 \\
\hline White Collar & 57 & 52.8 \\
\hline \multicolumn{3}{|l|}{ Family’s Income } \\
\hline Below RM1000 & 13 & 12.0 \\
\hline RM1001 To RM2500 & 23 & 21.3 \\
\hline RM2501 To RM4000 & 30 & 27.8 \\
\hline RM4001 To RM6000 & 28 & 25.9 \\
\hline Above RM6000 & 14 & 13.0 \\
\hline
\end{tabular}




\section{Reliability Coefficients}

The reliability coefficients of the study variables are shown in Table 2. It can be seen that the reliability coefficient of each study variable ranges from 0.79 to 0.93 , which exceeded Nunnally's (1978) minimum requirement of 0.70 .

To determine how well attitude and subjective norm predicted intention, the differential intention was regressed simultaneously on differential attitude and differential subjective norm. The regression result is presented in Table 3 .

The $R$-square value of 0.57 indicates that 57 percent of the variance in the de- pendent variable (differential intention) can be explained by the two independent variables (attitude and subjective norm). This finding provided support for $H_{1}$ of this research. In terms of the relative predictive power of the two independent variables, namely, attitude toward the behavior and subjective norm on the choice decision to buy a premium or economic infant formula, it can be observed that the beta weight for subjective norm was larger (0.464) compared to that of attitude (0.375). This suggests that perceived expectations of significant others or reference groups and peer motivation plays a more dominant role in influencing choice decision

Table 2. Reliability Coefficients

\begin{tabular}{lc}
\hline \multicolumn{1}{c}{ Descriptions } & Cronbach Alpha \\
Beliefs (X) & 0.80 \\
Beliefs (Y) & 0.87 \\
Differential Beliefs & 0.85 \\
Outcomes Evaluation & 0.84 \\
Attitude (X) & 0.91 \\
Attitude (Y) & 0.92 \\
Differential Attitude & 0.93 \\
Normative Beliefs (X) & 0.79 \\
Normative Beliefs (Y) & 0.93 \\
Differential Normative Beliefs & 0.88 \\
Motivation To Comply & 0.81 \\
\hline
\end{tabular}

Table 3. Results of Multiple Regression for Intention vs. Attitude and Subjective Norm

\begin{tabular}{lc}
\hline Independent Variable & Std Beta \\
\cline { 3 - 3 } Attitude & $0.375^{* *}$ \\
Subjective Norm & $0.464^{* *}$ \\
$\mathrm{R}^{2}$ & 0.57 \\
Adj R & 0.56 \\
F Value & $69.89^{* *}$ \\
Durbin Watson & 1.68 \\
\hline
\end{tabular}

*** $\mathrm{p}<0.01$ 
Ramayah et al.-The Relationships between Belief, Attitude, ...

toward premium or economic infant formula as opposed to a person's personal beliefs system.

Additionally, the results obtained from Table 3 provided evidence to support $\mathrm{H}_{2}$ of the study. The standardized beta coefficient for the attitude component is positive (0.375). This value implies that the more positive is the attitude, the greater is the intention to perform the behavior. Similarly, the results obtained from Table 3 provided evidence to support $\mathrm{H}_{3}$ of this investigation. The standardized beta coefficient for the subjective norm component is again positive $(0.464)$ which implies that the more positive is the subjective norm, the greater is the intention to perform the behavior.

Discriminant analysis was undertaken to test whether behavioral intention can be discriminated in terms of whether a person will buy a premium or economic infant formula. Respondents' choice decisions were separated into 2 groups, namely group 1 (Premium) and group 2 (Economic). Data was split using a 70-30 ratio for analysis and validation. This was performed to test the internal validity of the model and assess its predictive accuracy. The summary results obtained from the discriminant analysis are depicted in Table 4 and Table 5.

As can be observed from Table 4 and Table 5, a discriminant model is said to exist given that the chi-square value of 30.89 is significant $(p<0.01)$. The hit ratio was 92.7 percent (analysis sample) and 89.6 percent (holdout sample). This indicates that by measuring intention, we can classify respondents according to their

Table 4. Hit Ratio For Cases Selected in The Analysis

\begin{tabular}{|c|c|c|c|}
\hline \multirow[t]{2}{*}{ Actual Group } & \multirow[t]{2}{*}{$\begin{array}{l}\text { No. of } \\
\text { Cases }\end{array}$} & \multicolumn{2}{|c|}{$\begin{array}{l}\text { Predicted Group } \\
\text { Membership }\end{array}$} \\
\hline & & Premium & Economic \\
\hline Premium & 52 & $\begin{array}{c}47 \\
(90.4)\end{array}$ & $\begin{array}{c}5 \\
(9.6)\end{array}$ \\
\hline Economic & 17 & $\begin{array}{c}0 \\
(0.0)\end{array}$ & $\begin{array}{c}17 \\
(100.0)\end{array}$ \\
\hline
\end{tabular}

Percentage of "grouped" cases correctly classified: 92.7 percent

Table 5. Hit Ratio For Cases Not Selected in The Analysis

\begin{tabular}{|c|c|c|c|}
\hline \multirow[t]{2}{*}{ Actual Group } & \multirow[t]{2}{*}{$\begin{array}{l}\text { No. of } \\
\text { Cases }\end{array}$} & \multicolumn{2}{|c|}{$\begin{array}{l}\text { Predicted Group } \\
\text { Membership }\end{array}$} \\
\hline & & Premium & Economic \\
\hline Premium & 19 & $\begin{array}{c}16 \\
(84.2)\end{array}$ & $\begin{array}{c}3 \\
(15.8)\end{array}$ \\
\hline Economic & 10 & $\begin{array}{c}0 \\
(0.0)\end{array}$ & $\begin{array}{c}10 \\
(100.0)\end{array}$ \\
\hline
\end{tabular}

Percentage of "grouped" cases correctly classified: 89.6 percent 
Gadjah Mada International Journal of Business, September 2004, Vol. 6, No. 3

Table 6. Comparison of Goodness of Measure

\begin{tabular}{|c|c|c|}
\hline Measure & Value & $\begin{array}{l}\text { Hit Ratio for } \\
\text { Holdout Sample }\end{array}$ \\
\hline Maximum Chance & 0.65 & $89.6 \%$ \\
\hline Proportional Chance & 0.55 & $89.6 \%$ \\
\hline Comparison with Hair et al. (1998) & $81.25 \%$ & $89.6 \%$ \\
\hline $25 \%$ higher than chance & & \\
\hline Press Q & & \\
\hline Table Value & \multicolumn{2}{|c|}{6.635} \\
\hline Calculated Value & \multicolumn{2}{|c|}{$18.24 * *$} \\
\hline
\end{tabular}

choice decision. The maximum chance criterion equals 65.0 percent and the proportional chance criterion equals 55.0 percent. According to Hair et al. (1998), since the hit ratio was higher than both the maximum chance criterion and the chance criterion by more than 25 percent $(1.25 \mathrm{x}$ $0.65=81.25 \%$ ), the model is said to have acceptable level of predictive accuracy. Press $Q$ equals 18.24 which is greater than $\mathrm{Q}=6.635\left(\chi^{2}, \mathrm{df}=1, \alpha=0.01\right)$. Thus, it can be concluded that the predictions are significantly better than chance. Additionally, since Press Q is greater than 6.635, the predictive validity is significant at the 0.01 level. The discriminant function has a canonical squared correlation equal to 0.64 and is statistically significant with Wilks' Lambda $=0.357,(p<0.01)$ indicating that 64 percent of the variance in choice can be explained by the discriminant function. In sum, the findings obtained from the discriminant analysis indicate that intention is a precursor to performing a particular behavior. This result provides support for $\mathrm{H}_{4}$ of the current study. This finding is consistent with those of previous researchers (for instance, Manstead et al. 1983; Gengler and Mulvey 1999; Ramayah et al. 2002; Ramayah et al. 2003).

\section{Analysis on Behavioral Beliefs, Normative Beliefs, Evaluation of Outcomes and Motivation to Comply}

In order to understand how respondents evaluate a particular attitude or their perceptions of significant referent's beliefs, the means for these beliefs were computed. The mean value and ranking for each of the associated beliefs is depicted in Table 7.

From Table 7, it can be seen that in choosing premium infant formulas, the three most dominant belief outcomes relate to: 1) brand trusted, 2) closest to breast milk, and 3) nutrients value. On the other hand, in choosing the economic infant formula, the three most dominant belief outcomes were: 1) availability, 2) affordable, and 3) nutrient content. In terms of outcomes evaluations, all beliefs outcomes were evaluated positively with nutrient content being ranked the highest. The dominant influenced normative beliefs for infant formula were parents or relatives, and doctors. In terms of motivation to comply, doctors have the strongest influence on mothers' selection of infant formulas. 
Ramayah et al.-The Relationships between Belief, Attitude, ...

Table 7. Mean and Rankings

\begin{tabular}{|c|c|c|c|c|}
\hline Variable & Mean & Ranking & Mean & Ranking \\
\hline & Brand $X$ & & Brand $Y$ & \\
\hline Belief Outcomes & Premium & & Economic & \\
\hline 1. Closest to breast milk & 1.03 & 2 & 0.29 & 7 \\
\hline $\begin{array}{l}\text { 2. Visible physical and mental } \\
\text { development }\end{array}$ & 0.85 & 5 & 0.38 & 5 \\
\hline 3. Nutrients content & 1.01 & 3 & 0.44 & 3 \\
\hline 4. Availability & 0.89 & 4 & 1.17 & 1 \\
\hline 5. Affordable & 0.23 & 7 & 1.09 & 2 \\
\hline 6. Quality & 0.85 & 6 & 0.36 & 6 \\
\hline 7. Brand trusted & 1.04 & 1 & 0.44 & 3 \\
\hline Normative Beliefs & & & & \\
\hline 1. Parent or relatives & 1.04 & 1 & 0.28 & 2 \\
\hline 2. Doctors & 0.82 & 2 & 0.30 & 1 \\
\hline 3. Nurses & 0.68 & 4 & 0.26 & 3 \\
\hline 4. Friends & 0.76 & 3 & 0.21 & 4 \\
\hline Outcomes Evaluations & & & & \\
\hline 1. Closest to breast milk & 1.51 & 3 & & \\
\hline 2. Visible physical and & & & & \\
\hline mental development & 1.44 & 4 & & \\
\hline 3. Nutrients content & 1.57 & 1 & & \\
\hline 4. Availability & 1.38 & 6 & & \\
\hline 5. Affordable & 1.40 & 5 & & \\
\hline 6. Quality & 1.53 & 2 & & \\
\hline 7. Brand trusted & 1.30 & 7 & & \\
\hline Motivation to Comply & & & & \\
\hline 1. Parent or relatives & 0.41 & 3 & & \\
\hline 2. Doctors & 1.02 & 1 & & \\
\hline 3. Nurses & 0.45 & 2 & & \\
\hline 4. Friends & 0.38 & 4 & & \\
\hline
\end{tabular}

The mean reported is based on the following scale: $(+2),(0)$ no opinion, $(-2)$

\section{Discussions, Implications, and Limitations}

The primary aim of this study is to explore how the TRA could facilitate in predicting choice decision of infant food formula among consumers (mothers) in Malaysia. The result of the regression analysis indicates that the TRA model was able to predict choice intention for infant formula selection by explaining 57 percent of the variance. Additionally, both attitude and subjective norm were the direct predictors of choice intention. This finding is consistent with earlier researchers (for instance, Jaccard and Davidson 
1975; Budd et al. 1983; Thompson et al. 1994; Kessler et al. 1995; Kloeblen and Thompson 1999). The beta weight for subjective norm was larger than attitude toward behavior implying that subjective norm would have a better predictive power in determining the choice decision on infant formula. One plausible reason may be attributed to the fact that the mothers sampled may lack of knowledge on infants' nutrient intakes. Under such circumstance, they are likely to seek other people for advice (such as parents, relatives, doctors, and nurses).

Results from the discriminant analysis performed showed that belief outcomes in evaluating a premium infant formula and economic infant formula were different. For premium infant formula, brand trusted, closest to breast milk and nutrients content were identified as the dominant attributes in the attitudinal component. In contrast, availability, affordability, and nutrients content were identified as the prime beliefs in evaluating economic infant formula.

From the theoretical point of view, the findings of the present study provides evidence of the utility of the Theory of Reasoned Action (TRA) in the prediction and understanding of choice behavior concerning infant food formula among Malaysian consumers. Since most researches on consumer behavior were derived from western cultures (for instance, Manstead et al. 1983; Kessler et al. 1995; Kloeblen and Thompson 1999) and somewhat little work has been conducted on Malaysian consumers (for example Ramayah et al. 2003; Ramayah et al. 2003) which have been known to abide to the eastern culture where people value family and family ties (Mansor 1992), the findings from this study were able to reaffirm the generalizability of the TRA model across culture.

From the practical perspective, given that mothers are likely to seek the advice of others (such as their own parents, relatives, doctors, and nurses), regarding their babies infant formula selection, marketers should focus their efforts towards educating these groups of people so that they are able to provide accurate information regarding infants' food nutrient consumption. Additionally, marketers for premium infant formulas should focus their product positioning based on the key determinants of consumers' decision namely nutrient contents and trusted brand. As for economic infant formulas, marketers should highlight the product pricing and availability in order for them to be competitive.

There are two limitations worth noting in this study. First, this investigation is limited in scope since the sample was derived from one particular state in Malaysia. Future studies may need to extend the sample to other states in order to increase the generalizability of the findings. Second, the subjects in this study consisted of mothers alone. It would be better for future researchers to gather information from married couples with babies given that decisions for each household are generally jointly made.

\section{References}

Ajzen, I., and M. Fishbein. 1980. Understanding Attitude and Predicting Social Behavior. Englewood Cliffs, NJ: Prentice-Hall.

Bass, F. M., and W. W. Talarzyk. 1972. An attitude model for the study of brand preference. Journal of Marketing Research 9: 93-96. 
Ramayah et al.-The Relationships between Belief, Attitude, ...

Beng, L. S. 2001. An investigation of Penang's resident perception and attitudes towards gambling activities and industry. Unpublished MBA Thesis. Penang: Universiti Sains Malaysia.

Brewer, J.L., A. J. Blake, S. A. Rankin, and L. W. Douglass. 1999. Theory of reasoned action predicts milk consumption in women. Journal of the American Dietetic Association 99(1): 39-48.

Budd, R., S. Bleiker, and C. Spencer. 1983. Exploring the use and non-use of marijuana as reasoned action : An application of Fishbein and Ajzen's methodology. Drug and Alcohol Dependence 11: 217-224.

Conner, M.T. 1993. Understanding determinants of food choice: Contribution from attitude research. British Food Journal 95 (9): 27-32.

Edwards, W. 1954. The theory of decision making. Psychological Bulletin 51: 380-417.

Fishbein, M. 1967. Reading in Attitude Theory and Measurement. New York: Wiley.

Fishbein, M. 1971. The search for attitudinal-behavioral consistency. In J. B. Cohen (ed.). Behavioral Science Foundations of Consumer Behavior. New York: The Free Press.

Fishbein, M., and I. Ajzen. 1975. Belief, Attitude, Intention and Behavior: An Introduction to Theory and Research. Massachusetts: Addison-Wesley.

Gengler, C.E., and M. S. Mulvey. 1999. A means-end analysis of mothers' infant feeding choices. Journal of Public Policy and Marketing 18 (2): 172-188.

Grube, J. W., M. Morgan, and S. T. McGree. 1986. Attitudes and normative beliefs as predictors of smoking intentions and behaviours: A test of three models. British Journal of Social Psychology 25: 81-93.

Hair, J.F. Jr, R. E. Anderson, R. I. Tatham, and W. C. Black. 1998. Multivariate Data Analysis. New York: Prentice-Hall, Inc.

Hajemi, H. 2000\). Consumer choice behaviour: A study of consumer choice preference of IPTA and IPTS. Unpublished MBA Thesis. Penang: Universiti Sains Malaysia.

Howard, J. A., and J. N. Sheth. 1969. The Theory of Buyer Behavior. New York: John Wiley and Sons.

Howard, J. A. 1989. Consumer Behavior In Marketing Strategy. Englewood Cliffs, NJ: Prentice-Hall.

Jaccard, J. H., and A. R. Davidson. 1975. A comparison of two models of social behavior: Results of a survey sample. Sociometry 38 (4): 497-517.

Kessler L. A., A. C. Gielen, M. Diener-West, and D. M. Paige. 1995. The effect of a woman's significant other on her breast-feeding decision. Journal of Human Lactation 11: 103-109.

King, J., and A. Ashworth. 1987. Historical review of the changing pattern of infant feeding in developing countries: The case of Malaysia, the Caribbean, Nigeria and Zaire. Social Science and Medicine 25 (12): 1307-1320. 
Kloeblen, A. S., and N. J. Thompson. 1999. Predicting breast-feeding intention among low income pregnant women: A comparison of two theoretical models. Health Education and Behavior 26 (5): 675-688.

Manderson, L. 1984. These are modern times: Infant feeding practice in Peninsular Malaysia. Social Science and Medicine 18 (1): 47-57.

Mansor, N. 1992. Building a multi-cultural team. In A. Abdullah (ed.) Understanding the Malaysian Workforce-Guidelines for Managers: 49-57. Kuala Lumpur: Malaysian Institute of Management.

Manstead, A. S. R., C. Proffitt, C., and J. L. Smart. 1983. Predicting and understanding mothers' infant-feeding intentions and behavior: Testing the theory of Reasoned action. Journal of Personality and Social Psychology 44: 657-671.

Matheny, R.J., M. F. Picciano, and L. Birch, L. 1987. Attitudinal and social influences on infant feeding preferences. Journal of Nutrition Education 19: 21-31.

Miniard P. W., and J. B. Cohen. 1981. An examination of the Fishbein-Ajzen behavioral intentions model's concepts and measures. Journal of Experimental Social Psychology 27: 309-339.

Nielsen, A. C. 1999. Infant Market Report. Malaysia: AC Nielsen.

Nunnally, J.C. 1978. Psychometric Theory (2 ${ }^{\text {nd }}$ Ed.). New York: McGraw-Hill.

Rosenberg, M. J. 1956. Cognitive structure and attitudinal affect. Journal of Abnormal and Social Psychology 53: 367-372.

Ramayah, T., A. M. Nasurdin, N. Noor, and H. Hasan. 2003. Students' choice intention of a higher learning institution: An application of the theory of reasoned action (TRA). Malaysian Management Journal 7 (1): 47-62.

Ramayah, T., A. M. Nasurdin, N. Noor, and S. B. Lim. 2002. Relationships between belief, attitude, subjective norm, intention, and behavior towards numbers gambling: The Malaysian context. Jurnal Bisnis Strategy VIII (10): 81-96.

Thompson, K.E., N. Haziris, and P. J. Alekos. 1994. Attitudes and food choice behaviour. British Food Journal 96 (11): 9-15.

Towler, G., and R. Shepherd. 1992. Modification of Fishbein and Ajzen's theory of reasoned action to predict chip consumption. Food Quality and Preference 3: 214222. 